\title{
A study on elevation of troponin I in ischemic stroke as an independent prognostic marker of outcomes
}

\author{
Pradeep Thapa $M D^{1}$, Jagdish Prasad Agrawal $M D^{2}$, Rajani Baniya $M B B S^{3}$ \\ ${ }^{1}$ Internal Medicine, College of Medical Sciences, Bharatpur, Nepal, ${ }^{2}$ Department of Neurology, Maharajgunj Medical
} Campus, Maharjgunj, Nepal, ${ }^{3}$ BP Smriti Hospital, Basundhara, Nepal

\section{Abstract}

Background: Stroke is the second leading cause of death worldwide, comprising approximately $10 \%$ of all deaths. A substantial number of stroke patients have elevated cardiac troponin levels and are associated with poorer prognosis.

Methods: This was a prospective observational study conducted for 1 year at Tribhuvan University Teaching Hospital, in which 101 acute ischemic stroke patients were enrolled. Data included vital signs, laboratory parameters, and clinical features evaluated at the time of admission. The National Institute of Health Stroke Scale (NIHSS) and modified Rankin scale (mRS) were used to assess stroke severity and outcomes.

Results: Elevated troponin I ( $>0.034 \mathrm{ng} / \mathrm{mL})$ was observed in eight $(7.9 \%)$ patients. Compared to patients with normal troponin I, patients with elevated troponin I were older(mean age 61vs 59.68 years), had higher blood glucose( 10.6 vs. $7.04 \mathrm{mmol} / \mathrm{L})$, higher median white blood cells( 9.3 vs. 8.9 1,000/m3) and creatinine levels(119.5 $\mu \mathrm{mol} / \mathrm{L}$ vs. $95.9 \mu \mathrm{mol} / \mathrm{L}$ ), higher mean NIHSS scores on admission(16 vs. 8.6), and discharge(14.5 vs. 6.8), higher median mRS scores( 4.13 vs. 1.8$)$ at discharge $(\mathrm{p}<0.001)$. Poor outcomes were observed in $34(33.66 \%)$ patients of 101 patients and death occurred in five (4.9\%) patients. Patients with abnormal troponin I had poorer outcomes than normal troponin I level patients $(\mathrm{p}=<0.001)$ and significantly higher deaths $(\mathrm{p}=0.006)$. Univariate analysis of continuous variables revealed that patients with poor outcomes compared to good outcomes had higher troponin levels $(0.029$ vs. $0.013 \mathrm{ng} / \mathrm{mL}, \mathrm{p}=0.001)$, creatinine levels $(113.5$ vs. $89.8 \mu \mathrm{mol} / \mathrm{L}, \mathrm{p}=0.007)$, NIHSS score on admission ( 13.4 vs. $5.10, \mathrm{p}<0.001)$, discharge $(12.4$ vs. $5.1, \mathrm{p}<0.001)$, and higher $\mathrm{mRS}$ scores at discharge (3.71 vs. 1.16, $\mathrm{p}<0.001$ ). Multiple logistic regression analysis revealed that NIHSS score on admission $>13$ (OR 15.902; $95 \% \mathrm{CI}[3.65-69.28], \mathrm{p}=<0.001$ ) and abnormal troponin I level, troponin I $>0.029 \mathrm{ng} / \mathrm{mL}$ (odds ratio[OR]:28.451; $95 \%$ CI $[2.785-290.6], \mathrm{p}=0.005)$ were significant predictors of poor outcomes. Significant predictor of in hospital mortality only included troponin I level $>0.04 \mathrm{ng} / \mathrm{mL}$ ( $0 \mathrm{R} 0.071 ; 95 \% \mathrm{CI}[0.005-1.037], \mathrm{P}=0.05)$.

Conclusion: Troponin I provide better information than age and other laboratory parameters in the prediction of outcomes of stroke. Elevation of troponin I during acute stroke is a strong predictor of both poor outcomes and in-hospital mortality.

Key words: Stroke, Troponin I

Access this article online

Website: https://www.nepjol.info/index.php/NJN

DOI: https://doi.org/10.3126/njn.v17i2.30224

HOW TO CITE

Thapa P, Agrawal J, Baniya R. A study on elevation of troponin $I$ in ischemic stroke as an independent prognostic marker of outcomes. NJNS. 2020;17(2):26-34

${ }^{1}$ ORCID iD: https://orcid.org/0000-0002-5072-183X

${ }^{2}$ ORCID iD: https://orcid.org/0000-0002-7707-7992

${ }^{3}$ ORCID iD: https://orcid.org/0000-0001-8995-932X

Copyright (C) 2020 Nepalese Society of Neurosurgeons (NESON)

ISSN: 1813-1948 (Print), 1813-1956 (Online)

This work is licensed under a Creative Commons Attribution-Non Commercial 4.0 International License.

\section{Introduction}

troke is the second leading cause of death in the world, comprising approximately $10 \%$ of all deaths. ${ }^{1}$ Serious cardiac events are common and begin to occur very early after stroke onset. Cardiac mortality is the second most common cause of death in this acute stroke population. ${ }^{2}$

\author{
Address for correspondence: \\ Dr. Pradeep Thapa \\ Lecturer, Internal Medicine \\ College of Medical Sciences \\ Bharatpur, Nepal \\ Contact number: +977- 98417348666/9842628262 \\ E-mail: pradeep_thapa69@hotmail.com
}


Cardiac troponin $\mathrm{T}$ or $\mathrm{I}$ is elevated in a substantial number of acute stroke patients. It is associated with a higher number of in-hospital cardiac complications and deaths. Compared to cardiac troponins other cardiac markers like CK-MB or myoglobins and ECG are less accurate. ${ }^{3}$ Cardiac troponins are important biomarkers of acute myocardial infarction and are routinely studied in ischemic heart disease. ${ }^{3-6}$ Cardiac indicators in acute ischemic stroke were first documented in the late 1970s. ${ }^{7}$

Elevated levels of cardiac troponin have been reported in $10-34 \%$ of patients with acute stroke. ${ }^{8}$ Increased troponin I after stroke is associated with elevated circulating levels of epinephrine through activation of the sympathetic nervous system. ${ }^{9}$ The sympathetic activation may be responsible for myocardial damage in acute stroke. ${ }^{10}$ The associated cardiac damage is in the form of myocytolysis with loss of cardiac myocytes in absence of specific structural cause. ${ }^{7}$

Available laboratory parameters, clinical features, and biomarkers during acute stroke provide valuable information when investigating the clinical outcomes after stroke. Some studies have reported an independent association of elevated troponin I with both case fatality $^{3,11}$ and the combined poor outcomes of mortality or disability. ${ }^{12,13}$ However, other investigators have found no independent association. ${ }^{9}$

In this study, we investigated whether certain clinical features and laboratory parameters, including troponin I, are predictive of outcomes in patients with acute stroke. Routine evaluation of troponin I in ischemic stroke patients in Nepal is yet not widely practiced. Evaluation of troponin I can help identify the patients at risk prompting further evaluation to prevent mortality and morbidity.

\section{Materials and Methods}

This prospective observational study was done at the Tribhuvan University Teaching Hospital, Kathmandu, Nepal, in patients with acute ischemic stroke. A total of 101 patients were enrolled in the study. This study was approved by the Institutional Review Board of the Institute of Medicine, ref no. 475(6-11-E $)^{2} / 073 / 074$. The sample size was calculated taking the prevalence of elevation of troponin I in ischemic stroke to be $18 \%$ and margin of error to be $7.5 \%$. using the formula . $^{8,11,14,15}$

\section{$\mathrm{n}=\mathrm{Z}^{2} \mathrm{pq} / \mathrm{E}^{2}$}

All adult patients who gave informed signed consent, with the diagnosis of acute ischemic stroke that was confirmed by clinical presentation and proof of an ischemic lesion and/or absence of a corresponding intracranial lesion other than infarction by brain computed tomography or magnetic resonance imaging were included in the study. Patients with history of myocardial infarction in the past 4 weeks and previous renal impairment were excluded from the study.

\section{Method of Collection of Data}

A detailed history including the presence of hypertension, diabetes mellitus, smoking, and alcohol intake was obtained, NIHSS scoring was done and underwent cardiac enzyme testing including troponin I level at the time of admission/ within 48 hours of admission regardless of the stroke onset, 12 lead electrocardiograph, and other investigations at the time of admission according to our institute's protocol. An adult who has smoked 100 cigarettes in his or her lifetime and either quit at the time of interview (former smoker) or continue smoking (current smoker), both were included. ${ }^{16}$ Blood pressure was recorded using the standard sphygmomanometer at brachial artery and radial artery was used to record the pulse manually.

The VitrosECi troponin I assay (Ortho-Clinical Diagnostics, Rochester NY, USA) was used to measure troponin I using an immunometric technique. The limit of detection (LoD) for the VITROS Troponin I ES test using human serum pools is $0.012 \mathrm{ng} / \mathrm{mL}(\mu \mathrm{g} / \mathrm{L})$, whereas the $99^{\text {th }}$ percentile upper reference level (URL) is 0.034 $\mathrm{ng} / \mathrm{mL}$. The VITROS Troponin I ES assay AMI cutoff is $0.120 \mathrm{ng} / \mathrm{mL}$. All patients were treated according to the protocol of our institute.

At the time of discharge, the patient was evaluated again and NIHSS and mRS scores were done. Mortality due to all causes during the hospital stay was recorded. Improvement in the National Institute of Health Stroke Scale(NIHSS) between admission and discharge was used to assess outcomes as well as the modified Rankin Scale(mRS) to assess outcomes as in the NINDS study. ${ }^{17} \mathrm{An} \mathrm{mRS}$ score $>2$ was considered to indicate poor outcomes. ${ }^{18}$ Clinical deterioration was defined in patients who demonstrated an increase of two or more points in the NIHSS score during the acute stage of stroke. ${ }^{19}$

\section{Statistical Analysis}

Data were analyzed using descriptive as well as analytical approaches. Continuous variables are presented as mean values and standard deviation (SD) for normally distributed data. Categorical variables are presented as absolute values and percentages. As most variables were normally distributed, comparisons between groups for continuous variables were made by Student t-test and ANOVA for independent samples, and Pearson's $\chi 2$ test or Fisher's exact test for categorical variables (as appropriate).

Significant predictors in the univariate analyses were transferred to dichotomous variables with the cut-off level according to the mean values of poor outcomes, and were 
subsequently included in a multiple logistic regression model to identify the most important factors associated with poor outcomes and in-hospital death. A $p$-value of less than 0.05 was considered to indicate statistical significance. All statistical analyses were performed using the statistical package SPSS (Version 20, SPSS Inc. Chicago, IL).

\section{Results}

A total of 101 patients with acute ischemic stroke were enrolled in the study, and clinical and demographic characteristics are presented below. The mean age was $59.78 \pm 18.005$. The mean age of patients in both groups of study was similar, as shown in table 1.

Of 101 stroke patients, 52 had large vessel atherosclerosis $(51.5 \%), 24$ had cardioembolic stroke (23.8), 13 patients had small vessel stroke (12.9\%), 11 had stroke due to undetermined cause $(10.9 \%)$, and 1 patient had stroke due to other determined etiology (1\%).The major risk factor for ischemic stroke was hypertension $(\mathrm{n}=21,20.79 \%)$, followed by smoking seen in 13 cases (12.87\%) and diabetes mellitus in 3 cases (3\%). In 18.81\% of cases, both smoking and HTN were present, while in 4 cases both DM and HTN were risk factors and in the other 4 cases, smoking, HTN, and DM were present. Troponin I was elevated in 8 cases $(7.9 \%)$ of acute ischemic stroke, as shown in figure 1.

Patients with abnormal troponin I had significantly higher blood glucose $(\mathrm{p}=0.033)$. However, patients with abnormal troponin I and normal troponin I had similar baseline heart rate $(\mathrm{p}=0.339)$, white blood cell count $(p=0.689)$, creatinine $(p=0.129)$, and age $(p=0.843)$. However, heart rate controlling drugs were being taken in the few patients $(n=9)$ in the normal troponin I group and none in the elevated troponin group.

Hemoglobin $(p=0.620)$ and hematocrit $(p=0.1360)$ were also not statistically different between the groups. In addition, patients with abnormal troponin I had a higher mean NIHSS score on admission (16) and on discharge (14.5) than patients with normal troponin I levels (8.66 and 6.89). The mean MRS score was higher (4.13) in patients with abnormal troponin I than in patients with normal troponin I levels $(1.84, \mathrm{p}=<0.001)$, as shown in table 1.

Troponin was elevated in 8 cases and 5 cases were associated with ECG changes and 3 had normal ECG despite elevated troponin I $(p=0.012)$. The most common ECG changes seen in acute ischemic stroke patients were atrial fibrillation $(n=20,19.8 \%)$, T wave inversion was seen in 6 cases $(5.9 \%)$, ST elevation, LBBB, RBBB was seen in 1 case each and 3 cases had features of $\operatorname{LVH}(3 \%)$ as shown in figure 2 .

Abnormal troponin I were common in patients with stroke due to large artery atherosclerosis $(3 / 52=5.7 \%)$ and cardioembolism $(3 / 24=12.5 \%)$ than in patients with stroke due to small vessel disease and other determined etiology according to TOAST classification ( $\mathrm{p}=0.890)$. Poor outcomes were observed in $34(33.66 \%)$ patients of 101 patients and death occurred in $5(4.9 \%)$ patients. Patients with abnormal troponin I had poorer outcomes than normal troponin I level patients $(\mathrm{p}<0.001)$, as shown in table 2 , and significantly higher deaths $(\mathrm{p}=0.006)$, as shown in table 3 . Length of hospital stay was similar in both groups ( 10.24 vs. $12, \mathrm{p}=0.50)$.

Univariate analysis of continuous variables revealed that patients with poor outcomes compared to good outcomes had higher troponin levels (0.029 vs. $0.013 \mathrm{ng}$ / $\mathrm{mL}, \mathrm{p}=0.001)$, creatinine levels ( 113.5 vs. $89.8 \mu \mathrm{mol} / \mathrm{L}$, $\mathrm{p}=0.007)$, NIHSS score on admission (13.4 vs. 5.10, $\mathrm{p}<0.001)$, discharge (12.4 vs. 5.1, $\mathrm{p}<0.001)$, and higher $\mathrm{mRS}$ scores at discharge (3.71 vs. $1.16, \mathrm{p}<0.001)$. Other variables including age, total count, hematocrit, blood glucose, and heart rate were similar between both the groups analysis. Dichotomous variables revealed that male sex and cardioembolic stroke were not associated with poor outcomes, as shown in table 2 .

In hospital, deaths were associated with higher total counts $(11904, p=0.02)$, creatinine levels $(158.6, p=0.001)$, and troponin I levels $(0.043 \mathrm{ng} / \mathrm{mL}, \mathrm{p}=0.016)$. NIHSS score on admission did not show a significant association with in-hospital mortality. Length of stay was also similar between the groups. Dichotomous analysis showed a significant correlation between death and cardioembolic stroke. Age and sex were not associated with in-hospital death, as shown in table 3 .

Multiple regression analysis of the significant dichotomous variables was done with cut-off levels according to the mean values of poor outcomes. Multiple logistic regression analysis revealed that NIHSS score on admission $>13$ (odds ratio [OR] 15.902; 95\%CI [3.6569.28], $\mathrm{p}=<0.001)$ and abnormal troponin I level, troponin $\mathrm{I}>0.029 \mathrm{ng} / \mathrm{mL}$ ) (odds ratio [OR]:28.451; 95\% CI [2.785290.6], $\mathrm{p}=0.005$ ) were significant predictors of poor outcomes; however, creatinine levels did not show any significance in predicting the outcomes, as shown in table 4. Only troponin I level $>0.04 \mathrm{ng} / \mathrm{mL}$ (odds ratio [0R] 0.071; 95\% CI [0.005-1.037], $\mathrm{P}=0.05$ ) was a significant predictor of in-hospital mortality, as shown in table 5. 


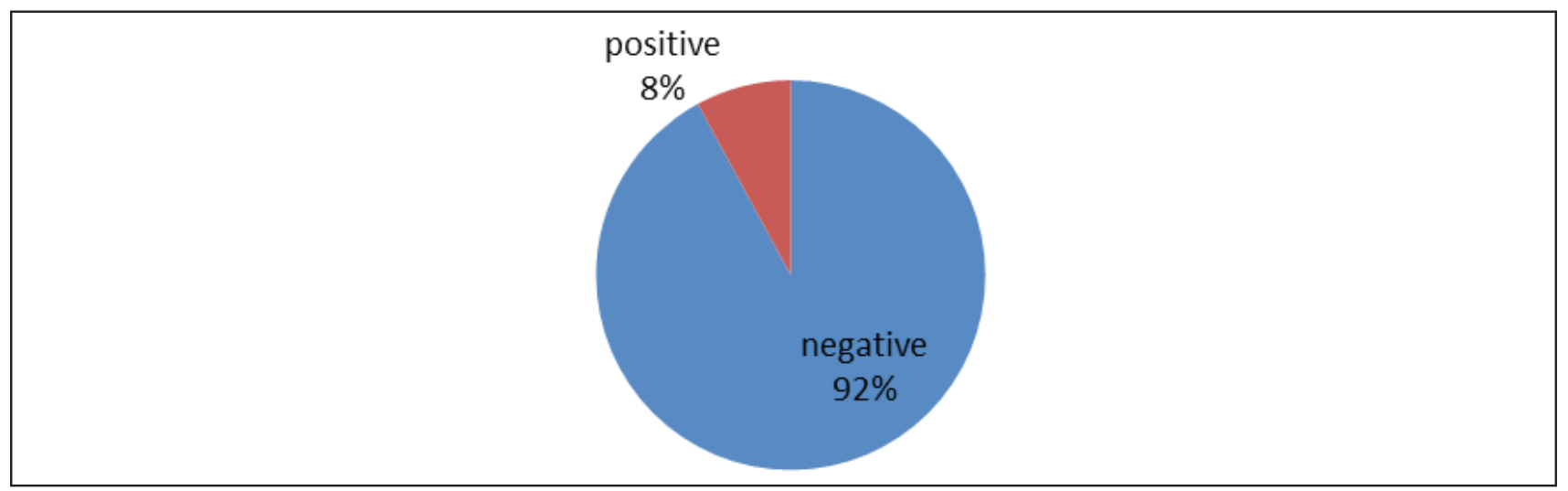

Figure 1: Prevalence of troponin I in ischemic stroke

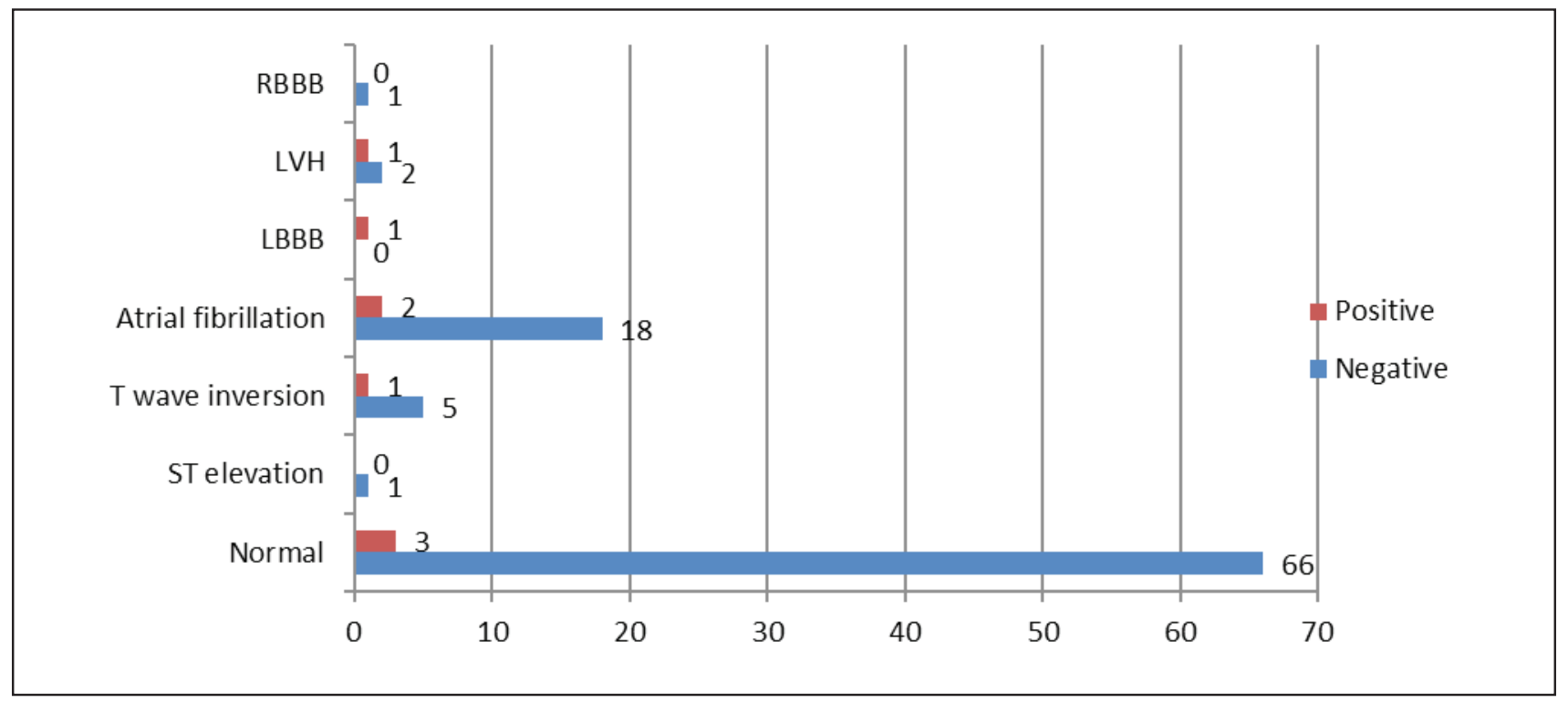

Figure 2: Relation between troponin I and ECG changes

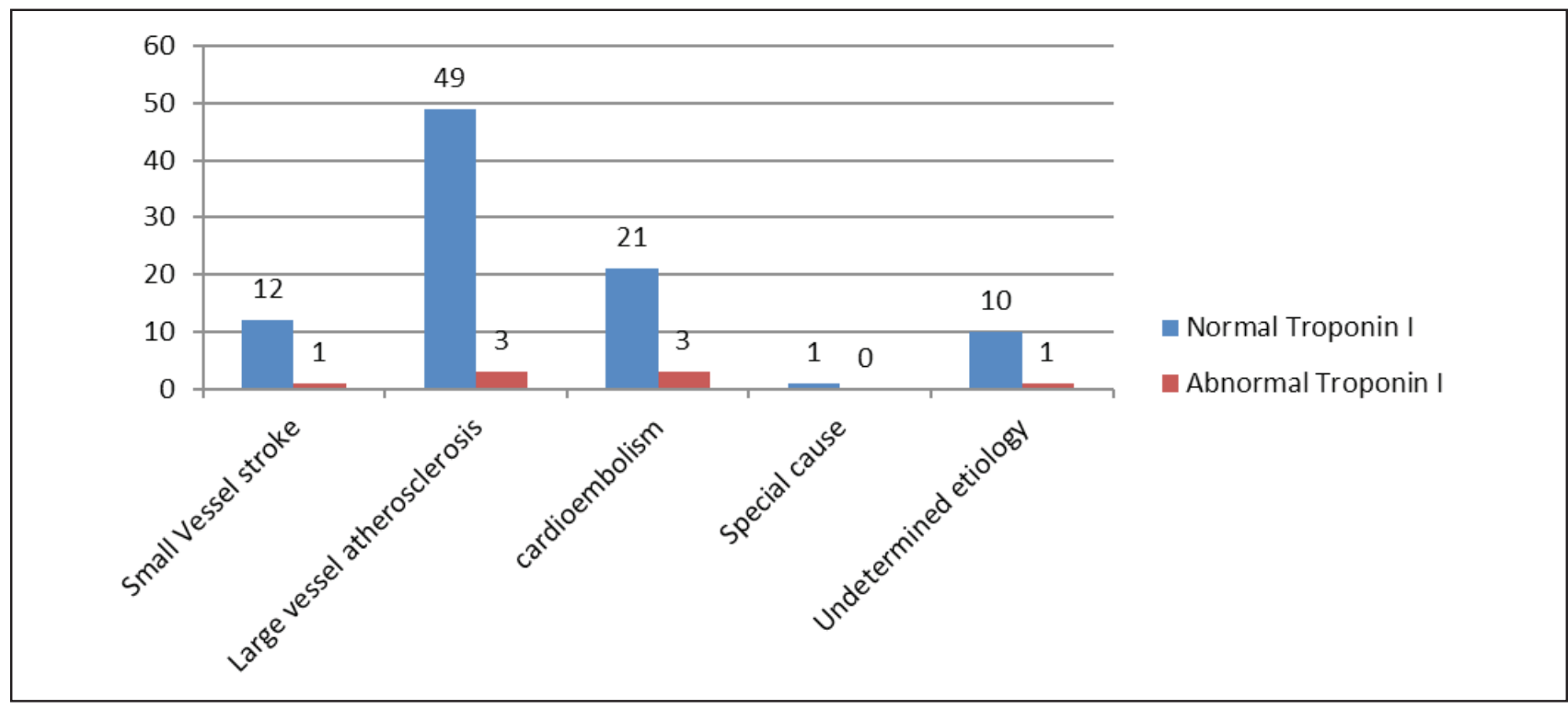

Figure 3: Relation between troponin I and type of stroke 


\begin{tabular}{|l|c|c|c|}
\hline \multicolumn{1}{c}{ Characteristics } & \multicolumn{3}{c}{ Troponin I test } \\
\cline { 2 - 4 } Mean age (years)** & Normal $(\mathbf{n = 9 3})$ & Abnormal $(\mathbf{n = 8})$ & P value \\
\hline Systolic pressure $(\mathrm{mmHg}) * *$ & $59.68 \pm 18.36$ & $61 \pm 13.98$ & 0.843 \\
\hline Diastolic pressure $(\mathrm{mmHg}) * *$ & $135.58 \pm 25.55$ & $121.25 \pm 21$ & 0.127 \\
\hline Heart rate $(\mathrm{Bpm}) * *$ & $84.19 \pm 14.98$ & $80 \pm 17.72$ & 0.456 \\
\hline White blood cells $\left(1000 / \mathrm{mm}^{3}\right)^{* *}$ & $83.58 \pm 11.61$ & $79.50 \pm 10.33$ & 0.339 \\
\hline Glucose(mmol/L)** & $8907.74 \pm 2861.83$ & $9368.75 \pm 4895.69$ & 0.683 \\
\hline Creatinine( $\mu$ mol/L)** & $7.04 \pm 3.71$ & $10.6 \pm 10.01$ & 0.033 \\
\hline NIHSS Score(on admission)** & $95.98 \pm 42.44$ & $119.5 \pm 29.73$ & 0.129 \\
\hline NIHSS Score(on discharge)** & $8.66 \pm 4.21$ & $16 \pm 7.61$ & $<0.001$ \\
\hline Modified Rankin Scale** & $6.89 \pm 4.32$ & $14.50 \pm 7.94$ & $<0.001$ \\
\hline Death* & $1.84 \pm 1.36$ & $4.13 \pm 1.24$ & $<0.001$ \\
\hline Poor outcome mRS $>2 *$ & 3 & 2 & 0.006 \\
\hline
\end{tabular}

Table 1: Comparison of clinical features, laboratory data, severity of stroke, and outcomes of patients with different levels of troponin I. Data presented as *number and ** Mean \pm S.D

\begin{tabular}{|c|c|c|c|}
\hline \multirow{2}{*}{ Characteristics } & \multicolumn{2}{|c|}{ Poor outcomes $(\mathrm{mRS}>2)$} & \multirow{2}{*}{ P value } \\
\hline & $\operatorname{Yes}(n=34)$ & $\operatorname{No}(n=67)$ & \\
\hline Mean Age(years)** & $58.97 \pm 18.74$ & $61.38 \pm 16.61$ & 0.527 \\
\hline Systolic pressure $(\mathrm{mmHg})^{* *}$ & $136.70 \pm 24.64$ & $130 \pm 26.74$ & 0.212 \\
\hline Diastolic pressure $(\mathrm{mmHg})^{* *}$ & $84.63 \pm 14.49$ & $82.35 \pm 16.52$ & 0.479 \\
\hline Heart rate $(\mathrm{Bpm})^{* *}$ & $83.94 \pm 10.94$ & $81.91 \pm 12.64$ & 0.406 \\
\hline White blood cells $(1000 / \mathrm{mm} 3)^{* *}$ & $8731.04 \pm 2938.88$ & $9364.41 \pm 3227.4$ & 0.325 \\
\hline Glucose $(\mathrm{mmol} / \mathrm{l}) * *$ & $7.23 \pm 4.22$ & $7.5 \pm 5.16$ & 0.784 \\
\hline Creatinine $(\mu \mathrm{mol} / \mathrm{L}) * *$ & $89.86 \pm 25.32$ & $113.58 \pm 60.55$ & 0.007 \\
\hline Troponin I(ng/mL)** & $0.013 \pm 0.0032$ & $0.029 \pm 0.038$ & 0.001 \\
\hline NIHSS Score(on admission)** & $7.10 \pm 3.51$ & $13.44 \pm 4.65$ & $<0.001$ \\
\hline NIHSS Score(on discharge)** & $5.10 \pm 3.085$ & $12.40 \pm 4.43$ & $<0.001$ \\
\hline Modified Rankin Scale** & $1.16 \pm 0.751$ & $3.71 \pm 1.06$ & $<0.001$ \\
\hline Length of stay(days)** & $9.43 \pm 4.18$ & $12.09 \pm 7.54$ & 0.025 \\
\hline Cardioembolism* & 12 & 12 & 0.158 \\
\hline Male sex* & 19 & 30 & 0.291 \\
\hline
\end{tabular}

Table 2: Correlation of the factors affecting the outcomes of ischemic stroke.

Data presented as *number (percent) and **mean \pm S.D.

\begin{tabular}{|c|c|c|c|}
\hline \multirow{2}{*}{ Characteristics } & \multicolumn{2}{|r|}{ Death } & \multirow{2}{*}{ P value } \\
\hline & $\operatorname{Yes}(\mathbf{n}=\mathbf{5})$ & $\operatorname{No}(n=96)$ & \\
\hline Mean Age(years)** & $69.00 \pm 19.33$ & $59.30 \pm 17.91$ & 0.242 \\
\hline Systolic pressure $(\mathrm{mmHg})^{* *}$ & $128 \pm 19.235$ & $134.78 \pm 25.74$ & 0.564 \\
\hline Diastolic pressure $(\mathrm{mmHg})^{* *}$ & $84 \pm 23.02$ & $83.85 \pm 14.82$ & 0.983 \\
\hline Heart rate $(\mathrm{Bpm})^{* *}$ & $85.6 \pm 4.09$ & $83.14 \pm 11.77$ & 0.643 \\
\hline White blood cells $\left(1000 / \mathrm{mm}^{3}\right)^{* *}$ & $11904 \pm 5443.97$ & $8790.10 \pm 2825.07$ & .025 \\
\hline Glucose $(\mathrm{mmol} / \mathrm{l})^{* *}$ & $5.94 \pm 1.11$ & $7.39 \pm 4.64$ & 0.220 \\
\hline Creatinine $(\mu \mathrm{mol} / \mathrm{L})^{* *}$ & $158.6 \pm 98.28$ & $94.68 \pm 35.24$ & 0.001 \\
\hline Troponin I(ng/mL)** & $0.043 \pm 0.037$ & $0.01743 \pm 0.022$ & 0.016 \\
\hline NIHSS Score(on admission) ${ }^{* *}$ & $10.80 \pm 7.25$ & $9.16 \pm 4.824$ & 0.470 \\
\hline Modified Rankin Scale** & 6 & $1.81 \pm 1.199$ & $<0.001$ \\
\hline
\end{tabular}


Elevation of troponin I in ischemic stroke

\begin{tabular}{|l|c|c|r|}
\hline Length of stay(days)** & $12.00 \pm 12.787$ & $10.24 \pm 5.15$ & 0.500 \\
\hline Cardioembolism* & $2(40 \%)$ & $22(22.9 \%)$ & $<0.001$ \\
\hline Male gender* & $3(60 \%)$ & $46(47.9 \%)$ & 0.598 \\
\hline
\end{tabular}

Table 3: Correlation of clinical features and in-hospital mortality in 101 acute ischemic stroke patients. Data presented as

$*_{\text {number (percent) and } * * \text { mean } \pm \text { S.D. }}$

\begin{tabular}{|c|c|c|c|c|c|c|c|c|}
\hline \multirow{2}{*}{ Characteristics } & \multirow{2}{*}{ B } & \multirow{2}{*}{ S.E. } & \multirow{2}{*}{ Wald } & \multirow{2}{*}{ Df } & \multirow{2}{*}{ P value } & \multirow{2}{*}{ Expo (B) } & \multicolumn{2}{|c|}{$95 \%$ CI for EXP(B) } \\
\hline & & & & & & & Lower & Upper \\
\hline NIHSS score on admission $>13$ & 2.766 & 0.751 & 13.572 & 1 & 0.000 & 15.902 & 3.650 & 69.287 \\
\hline Creatinine $>113 \mu \mathrm{mol} / \mathrm{L}$ & 1.047 & 0.870 & 1.450 & 1 & 0.229 & 2.849 & 0.518 & 15.661 \\
\hline Troponin I $>0.029 \mathrm{ng} / \mathrm{mL}$ & 3.348 & 1.186 & 7.974 & 1 & 0.005 & 28.451 & 2.785 & 290.63 \\
\hline Constant & 9.417 & 1.943 & 23.501 & 1 & 0.000 & 0.000 & & 4 \\
\hline
\end{tabular}

Table 4: Regression model of factors influencing outcomes in 101 patients with acute ischemic stroke

\begin{tabular}{l|c|c|c|c|c|c|}
\hline \multirow{1}{*}{ Characteristics } & \multirow{2}{*}{ Std. Error } & \multirow{2}{*}{ Wald } & \multirow{2}{*}{ Sig. } & \multirow{2}{*}{ Expo(B) } & \multicolumn{2}{|c|}{ 95\% confidence interval for Expo(B) } \\
\cline { 6 - 7 } & & & & & Lower & Upper \\
\hline TotalWBC $>11900$ & 1.117 & 3.037 & 0.081 & 0.143 & 0.016 & 1.275 \\
\hline Creatinine $>158 \mu \mathrm{mol} / \mathrm{L}$ & 1.328 & 3.347 & 0.067 & 0.088 & 0.007 & 1.189 \\
\hline Troponin I $>0.04 \mathrm{ng} / \mathrm{mL}$ & 1.368 & 3.737 & 0.05 & 0.071 & 0.005 & 1.037 \\
\hline
\end{tabular}

Table 5: Regression model of factors influencing deaths in patients with acute ischemic stroke

\section{Discussions}

This study demonstrates the prognostic significance of elevated troponin in patients with ischemic stroke. Patients with increased troponin I had increased chances of unfavorable functional outcomes at discharge and mortality. Troponin I is a highly sensitive and specific marker of acute myocardial infarction. Hence other cardiac biomarkers were not considered for evaluation in this study. Elevated troponin I is characteristic of a number of cardiac diseases as well such as heart failure, pericarditis, myocarditis, atrial fibrillation, and tachycardia. Elevated troponin I has also been found in patients with chronic renal failure, sepsis, critical illness, pulmonary embolism, chronic obstructive pulmonary disease, and stroke. ${ }^{20}$

Elevated levels of cardiac troponin have been reported in $10-34 \%$ of patients with acute stroke. Kerr et al. (2009) conducted a systematic review of studies measuring troponin within seven days of symptom onset in acute stroke patients and found that more than $18 \%$ of patients had a high troponin level. ${ }^{8}$ Some studies reported that elevated troponin levels were more common in patients with stroke due to cardioembolism, who also had evidence of atrial fibrillation, ischemic heart disease, or heart failure. ${ }^{4,21,22}$

Abnormal troponin I levels were observed in $7.9 \%$ of the patients in our study. We found that patients with abnormal troponin I were more likely to have large artery atherosclerosis and cardioembolism. Patients with elevated troponin I levels were older and had higher creatinine levels and blood glucose levels than patients with normal troponin I levels. Patients with elevated troponin I presented with more severe initial stroke severity. Worse outcomes and higher in-hospital mortality were observed in patients with abnormal troponin I, similar to those reported by Di Angelantonio et al. ${ }^{23}$

Increase in catecholamine release as a result of hypo-perfusion of the posterior hypothalamus occurs in neurologic causes resulting in autonomic nervous system imbalance and increased sympathetic output. ${ }^{24}$ Involvement of the insular cortex is known to be associated with more frequent occurrences of cardiac complications after acute stroke. ${ }^{25}$ Brain magnetic resonance imaging to identify the precise location of the stroke was not performed in all patients; therefore, we were not able to analyze the involvement of the insular or parietal cortex.

Higher troponin levels were associated with the severity of stroke rather than the location of stroke. Abnormal troponin levels were more likely to be due to cardiac and renal causes than the cerebral causes. ${ }^{26}$ The average age of patients with abnormal troponin I, patients with poor outcomes, and patients who died in the hospital in this study was approximately 65 years. Faiz et al. reported that age $\geq 76$ years was independently associated with elevated troponin levels in patients with acute ischemic stroke. But in our study, age was not significantly different between the groups. ${ }^{22}$ 
In our study, blood glucose was significantly elevated in the positive troponin I group however was not associated with poor outcomes. Similarly, elevated creatinine level $>112 \mu \mathrm{mol} / \mathrm{L}$ at the time of admission was associated with poor outcomes of stroke. Bashair et al. showed that elevated creatinine levels at the time of admission were associated with increased mortality in stroke patients. ${ }^{27}$

With the exception of the NIHSS score on admission, only elevated troponin I was a strong independent predictor of both poor outcomes and death. Abnormal troponin I had an OR of 28.451 for poor outcomes and an OR of 0.071 for in-hospital mortality. Meta-analysis by Kerr et al. (2009) analyzed 2901 patients from 15 different studies including different definitions and timing for troponin evaluation. Irrespective of different definitions and sampling times, elevated troponin is associated with poor outcomes. ${ }^{8}$

Elevation of troponin level has been associated with increased risk of mortality and disability compared to other factors as shown in multiple studies..$^{11,28,29}$ In the present study, abnormal troponin I was a predictor of both poor outcomes and in-hospital mortality. An NIHSS score $\geq 12$ on admission was also a strong predictor of both poor outcomes and in-hospital mortality.

The American Stroke Association recommends the routine checking of markers of cardiac ischemia during acute stroke. ${ }^{30}$ Noninvasive echocardiography, cardiac magnetic resonance imaging, or computed tomography may help to identify possible unstable coronary disease, heart failure, or cardiomyopathy. The TRELAS study done in acute ischemic stroke patients with elevated troponin level and patients with non-ST-elevation acute coronary syndromes revealed that $48 \%$ of acute ischemic stroke patients had no coronary culprit lesion compared to $13 \%$ in non-ST-elevation-acute coronary syndromes patients following coronary angiography. ${ }^{14}$

The high-sensitivity assay of troponin allows for precise detection of troponin even at concentrations tenfold lower than conventional assays. ${ }^{31}$ Dynamic changes in the troponin levels $(>50 \%)$ within 24 hour in stroke patients were better indicator for in-hospital mortality than the patients whose troponin levels were elevated but remain stable. ${ }^{26}$ Serial measurements should be performed to establish whether troponin is acutely or chronically elevated.

\section{Limitations}

This study has a number of limitations. Cardiac illness like cardiomyopathy and heart failure were not excluded from the study. Troponin was only examined in a subgroup of patients and was not systematically assessed in all patients presenting with ischemic stroke. Troponin I was checked only once in each patient in the emergency room without a known lag time between exact time period of onset of symptoms and troponin measurement, without dynamic assessment. Besides as an exclusion criterion, renal impairment was evaluated based on historical diagnosis in the past and raised serum creatinine value rather than calculation of eGFR. The low number of patients with outcome "death" might limit meaningfulness. Finally, there is a lack of follow-up data on functional outcomes after discharge.

\section{Conclusions}

Elevation of troponin $I$ in ischemic stroke independently predicted unfavorable functional outcomes at discharge and in- hospital mortality. Compared to other laboratory parameters, troponin I is a better predictor of outcomes of stroke. Careful and prompt evaluation of patients with acute stroke is needed in the setting of elevated troponin I.

Acknowledgements: The authors are grateful to all the patients who consented to this study. We would also like to thank all the faculty members of the Department of Neurology for their help during this study. The authors thank the Department of Community Medicine for their help and suggestions in the statistics.

\section{Conflict of Interest: None \\ Source(s) of support: None}

\section{References}

1. Deresse B, Shaweno D. Epidemiology and in-hospital outcome of stroke in South Ethiopia. J Neurol Sci. 2015;355(1-2):138-42. https://doi.org/10.1016/j. jns.2015.06.001

2. Prosser J, MacGregor L, Lees KR, Diener H-C, Hacke W, Davis S. Predictors of early cardiac morbidity and mortality after ischemic stroke. Stroke. 2007 Aug;38(8):2295-302.https://doi.org/10.1161/ STROKEAHA.106.471813

3. Di Angelantonio E, Fiorelli M, Toni D, Sacchetti ML, Lorenzano S, Falcou A, et al. Prognostic significance of admission levels of troponin I in patients with acute ischaemic stroke. J Neurol Neurosurg Psychiatry. 2005;76:76-81. https://doi.org/10.1136/ jnnp.2004.041491

4. Faiz KW, Thommessen B, Einvik G, Omland T, Rønning OM. Prognostic value of high-sensitivity cardiac troponin $\mathrm{T}$ in acute ischemic stroke. J Stroke 
Cerebrovasc Dis. 2014;23(2):241-8. https://doi. org/10.1016/j.jstrokecerebrovasdis.2013.01.005

5. Providência R, Barra S, Paiva L. Atrial fibrillation, elevated troponin, ischemic stroke and adverse outcomes: Understanding the connection. Clin Res Cardiol. 2013;102(10):701-11. https://doi. org/10.1007/s00392-013-0591-0

6. Scheitz JF, Endres M, Mochmann HC, Audebert HJ, Nolte $\mathrm{CH}$. Frequency, determinants and outcome of elevated troponin in acute ischemic stroke patients. Int J Cardiol. 2012;157(2):239-42. https://doi. org/10.1016/j.ijcard.2012.01.055

7. Norris JW, Kolin A, Hachinski VC. Focal myocardial lesions in stroke. In: Stroke. Amer Heart Assoc 7272 Greenville Vvenue, Dallas, TX 75231-4596; 1980. p. 130.

8. Kerr G, Ray G, Wu O, Stott DJ, Langhorne P. Elevated troponin after stroke: A systematic review. Cerebrovasc Dis. 2009;28(3):220-6. https:/doi. org/10.1159/000226773

9. Barber M, Morton JJ, Macfarlane PW, Barlow N, Roditi G, Stott DJ. Elevated troponin levels are associated with sympathoadrenal activation in acute ischaemic stroke. Cerebrovasc Dis. 2007;23(4):260 6. https://doi.org/10.1159/000098325

10. Hachinski VC, Smith KE, Silver MD, Gibson CJ, Ciriello J.Acute myocardial and plasma catecholamine changes in experimental stroke. Stroke. 1986;17(3): 387-90. https://doi.org/10.1161/01.STR.17.3.387

11. Jensen JK, Kristensen SR, Bak S, Atar D, HoilundCarlsen PF, Mickley H. Frequency and significance of troponin $\mathrm{T}$ elevation in acute ischemic stroke. Am J Cardiol. 2007;99(1):108-12. https://doi. org/10.1016/j.amjcard.2006.07.071

12. Fure B, Bruun Wyller T, Thommessen B. Electrocardiographic and troponin T changes in acute ischemic stroke. J Intern Med. 2006;259(6):592-7. https://doi.org/10.1111/j.1365-2796.2006.01639.x

13. Christensen $\mathrm{H}$, Johannesen $\mathrm{HH}$, Christensen AF, Bendtzen K, Boysen G. Serum cardiac troponin I in acute stroke is related to serum cortisol and TNF- $\alpha$. Cerebrovasc Dis. 2004;18(3):194-9. https://doi. org/10.1159/000079941

14. MochmannH-C, ScheitzJF, Petzold GC, Haeusler KG, Audebert HJ, Laufs U, et al. Coronary Angiographic Findings in Acute Ischemic Stroke Patients With Elevated Cardiac troponin clinical perspective. Circulation. 2016;133(13):1264-71. https://doi. org/10.1161/CIRCULATIONAHA.115.018547

15. Newby LK, Jesse RL, Babb JD, Christenson RH, De Fer TM, Diamond GA, et al. ACCF 2012 Expert Consensus Document on Practical Clinical
Considerations in the Interpretation of Troponin Elevations. J Am Coll Cardiol. 2012;60(23):2427 LP - 2463. https://doi.org/10.1016/j.jacc.2012.08.969

16. NHIS-Adult Tobacco Use-Glossary. Centers for Disease Control and Prevention(CDC). https://www. cdc.gov/nchs/nhis/tobacco/tobacco_glossary.html

17. Adams RJ. Management issues for patients with ischemicstroke.Neurology.1995;45(2Suppl1):S15-8. http://europepmc.org/abstract/MED/7885585

18. Banks JL, Marotta CA. Outcomes validity and reliability of the modified rankin scale: Implications for stroke clinical trials - A literature review and synthesis. Stroke. 2007;38(3):1091-6. https://doi. org/10.1161/01.STR.0000258355.23810.c6

19. Siegler JE, Boehme AK, Kumar AD, Gillette MA, Albright $\mathrm{KC}$, Martin-Schild S. What change in the national institutes of health stroke scale should define neurologic deterioration in acute ischemic stroke? J Stroke Cerebrovasc Dis. 2013;22(5):67582. https://doi.org/10.1016/j.j stroke cerebrovas dis.2012.04.012

20. Tanindi A, Cemri M. Troponin elevation in conditions other than acute coronary syndromes. Vascular Health and Risk Management. 2011; 7:597-603. https://doi.org/10.2147/VHRM.S24509

21. Etgen T, Baum H, Sander K, Sander D. Cardiac troponins and N-terminal pro-brain natriuretic peptide in acute ischemic stroke do not relate to clinical prognosis. Stroke. 2005;36(2):270-5. https:// doi.org/10.1161/01.STR.0000151364.19066.a1

22. Faiz KW, Thommessen B, Einvik G, Brekke PH, Omland T, Ronning OM. Determinants of high sensitivity cardiac troponin $\mathrm{T}$ elevation in acute ischemic stroke. BMC Neurol. 2014; 14:96. https:// doi.org/10.1186/1471-2377-14-96

23. Maliszewska M, Fiszer U, Palasik W, Morton M, Tadeusiak W. Elevated troponin I level-a predictor of poor prognosis after ischemic stroke. Postępy Nauk Med. 2013.

24. Samuels MA. The Brain-Heart Connection Circulation. 2007;116(1):77 LP - 84. http://circ. ahajournals.org/content/116/1/77.abstract

25. Oppenheimer S. The insular cortex and the pathophysiology of stroke-induced cardiac changes. Can J Neurol Sci. 1992;19(2):208-11.

26. Abdi S, Oveis-Gharan S, Sinaei F, Ghorbani A. Elevated troponin $\mathrm{T}$ after acute ischemic stroke: Association with severity and location of infarction. Iran J Neurol. 2015;14(1):35-40. http://www.ncbi. nlm.nih.gov/pmc/articles/PMC4395805/

27. Lee S, Lee Y, Jang H, Moon H, Kim DK, Han SS. Heart rate is associated with mortality in patients 
undergoing continuous renal replacement therapy. Kidney Res Clin Pract. 2017;36(3):250-6. https:// doi.org/10.23876/j.krcp.2017.36.3.250

28. Scheitz JF, Nolte CH, Laufs U, Endres M. Application and Interpretation of High-Sensitivity Cardiac Troponin Assays in Patients with Acute Ischemic Stroke. Stroke. 2015;46(4):1132-40. https://doi. org/10.1161/STROKEAHA.114.007858

29. Maoz A, Rosenberg S, Leker RR. Increased HighSensitivity Troponin-T Levels Are Associated with Mortality After Ischemic Stroke. J Mol Neurosci. 2015;57(2):160-5. https://doi.org/10.1007/s12031015-0593-7
30. Adams HPJ, del Zoppo G, Alberts MJ, Bhatt DL, Brass L, Furlan A, et al. Guidelines for the early management of adults with ischemic stroke: a guideline from the American Heart Association/ American Stroke Association Stroke Council, Clinical Cardiology Council, Cardiovascular Radiology and Intervention Council, and the Atheros. Circulation. 2007;115(20):e478-534. https://doi.org/10.1161/ CIRCULATIONAHA.107.181486

31. Ibrahim B, Rayyis L, Almekhlafi M. Elevated Serum Creatinine Predicts Higher Mortality in Stroke Patients (P3.254). Neurol. 2017;88(16 Supplement). http://www.neurology.org/content/88/16 Supplement/P3.254.abstract 